\title{
TERRITÓRIO, IMPÉRIO E NAÇÃO: geopolítica em Paul Vidal de La Blache
}

Guilherme Ribeiro

Prof. Instituto de Ciências da Sociedade e Desenvolvimento Regional da UFF, Campos Goytacazes geofilos@ig.com.br

Resumo

O objetivo deste artigo é interpretar a reflexão geopolítica no pensamento de Paul Vidal de la Blache, um tema pouco explorado até aqui. Admitindo a geografia como estratégia de sobrevivência não apenas de grupos sociais mas também de Estados Nacionais, Vidal de la Blache acompanha atentamente os interesses territoriais da França na Europa, na África e nas Américas no âmbito do Colonialismo.

Palavras-chave: Vidal de la Blache; geopolítica; França; Europa; Colonialismo.

\section{Abstract}

The aim of this article is to interpretate the geopolitics in Paul Vidal de la Blache's thought - a topic little explored until now. Assuming geography as a survival strategy not only social groups but also of Nation States, Vidal de la Blache closely monitoring the territorial interests of France in Europe, Africa and the Americas under Colonialism.

Key Words: Vidal de la Blache; geopolitics; French; Europe; Colonialism.

\section{INTRODUÇÃO}

Simbolizando as mudanças no interior da história do pensamento geográfico, em um de seus últimos livros Paul Claval repassa o domínio de conhecimento a que dedicou a maior parte de sua trajetória intelectual de maneira reveladora: primeiramente, afirma que, quando estudante, a história da Geografia não era ensinada, não passava de mera digressão dos professores. O que indica, no mínimo, sua irrelevância, o descaso dos antigos mestres em preocupar-se sistematicamente com os caminhos e descaminhos do campo disciplinar que os justificava. A seguir, amparado por quarenta anos de distância, confessa que a história da geografia clássica na França e no exterior lhe parece, hoje, muito mais complexa do que pensava recentemente (CLAVAL, 2007:16 e 63).

Dilatando um pouco mais a questão, pode-se dizer que estamos atravessando um caminho de - no mínimo - três vias que, em um determinado ponto, se encontram: (i) o debate Modernidade vs. PósModernidade; (ii) um despontar de temas geográficos entre as Ciências Sociais e mesmo no domínio público, por conta da Globalização e de tudo aquilo que ela acarreta; e (iii) uma releitura da geografia clássica francesa associada ao Colonialismo .

Retenhamos o terceiro tópico a fim de ampliar uma rota assaz importante — porém ainda muito pouco explorada: os aspectos geopolíticos da obra de Paul Vidal de la Blache (1845-1918). Para enfatizar uma das polêmicas ao redor de Vidal, recordemos o tournant interpretativo protagonizado pelo geógrafo francês Yves Lacoste em seu tão famoso livro La Géographie, ça sert, d'abord, à faire la guerre (LACOSTE, 1988 [1976]). No intuito de sublinhar a dimensão estratégica relativa ao espaço, bem como contribuir para o desenvolvimento de uma reflexão marxista em torno do mesmo, ele volta suas críticas à Geografia clássica. Entre outros fatores, reclama do descritivismo e do empirismo, cristalizando seu argumento na afirmação de que tudo não passava de uma operação ideológica a propagar uma geografia dos "professores" mnemônica e insípida e mascarar uma geografia dos "Estados-Maiores", cujo objetivo primeiro seria promover a guerra.

Posto isso, quando vem a público uma edição ampliada do livro em tela, tal não foi a surpresa quando Lacoste (ele mesmo surpreso!) relata a "descoberta" de La France de l'Est, obra "esquecida" pelos ge- 
ógrafos franceses em que Vidal estuda a questão da fronteira franco-alemã em torno de Alsácia-Lorena, rica em carvão e minério de ferro (VIDAL DE LA BLACHE, 1994 [1917]). Ou seja, surgia uma faceta "desconhecida" (as aspas são nossas) do pensamento vidaliano: a geopolítica (LACOSTE, 1988 [1976]). E, por esta razão, Lacoste, gentilmente, reabilita-o - não somente reeditando o livro "perdido" mas redigindo prefácio elogioso (LACOSTE, 1994).

Este artigo, que pretende ser apenas uma introdução à geopolítica vidaliana, visa mostrar que este tema nem surgiu "do nada" e nem poderia ter sido "descoberto", uma vez que sempre esteve presente em seu pensamento: da aula inaugural em Nancy sobre a relevância do Mediterrâneo logo após a guerra franco-prussiana, passando pela preocupação com as fronteiras da França em États et nations de l'Europe autour de France até chegar ao balanço das perdas territoriais para a Alemanha em La France de l'Est (Lorraine-Alsace), a geografia enquanto estratégia e disputa por regiões e territórios atravessa do início ao fim a obra de Vidal (VIDAL DE LA BLACHE, 1873, 1889, 1994 [1917]).

Recorrendo aos Annales de Géographie entre os anos de 1891 e 1918 - sobretudo à seção Notes et correspondance -, encontramos uma série de resenhas e mesmo alguns textos que passaram despercebidos por alguns estudiosos do pensamento geográfico, tanto na França quanto em outros países. São reflexões capitais que assinalam, entre outras questões, suas referências de leitura naquele momento e seu posicionamento frente à empresa colonial. Encontramos um geógrafo motivado com a fauna, flora, hidrografia, geologia e geomorfologia de outras áreas, procurando fazer comparações de como tais aspectos se apresentavam na Europa. Mas também um intelectual engajado e, por isso, preocupado com a economia, a política e as formas de penetração francesa em território africano. Observando tanto as medidas de seu Império quanto do Britânico, seja na África ou na América do Sul, tratava-se de salvaguardar os interesses franceses. Por fim, encerraremos esta investigação com uma análise das questões geopolíticas presentes em La France de l'Est.

\section{A GEOGRAFIA COMO ESTRATÉGIA: um outro olhar sobre Vidal de la Blache}

Vidal é, antes de tudo, um estrategista. Não no sentido de debruçar-se sobre a Geografia para fazer dela um instrumento de combate, mas sim no esforço de fazê-la uma ciência voltada para o conhecimento das características físicas da superfície terrestre e suas especificidades regionais (RIBEIRO, 2010a). Tais características são matrizes com as quais as civilizações se defrontam no decorrer de sua história, e que, para conviver com elas ou mesmo superá-las, precisam construir artifícios capazes de permitir sua reprodução. Portanto, a Geografia diz respeito ao estudo das distintas estratégias civilizacionais de desenvolvimento, das táticas que são forjadas na relação com o habitat. Há uma disputa pela vida, cujo desdobramento geográfico é, precisamente, a habilidade de se relacionar com o meio de maneira a otimizálo o quanto possível. Dada a evidência que os lugares não são "auto-sustentáveis", ou seja, não possuem a totalidade das condições físicas e humanas necessárias para a sobrevivência de suas populações, há uma dependência entre eles onde, inevitavelmente, as escalas se articulam. Por sua vez, a extensão de tal articulação dependerá da combinação entre a capacidade técnica e o sítio em que os grupos sociais estão inscritos. Esta combinação, decerto, engloba uma série de fatores, como a transformação da paisagem, a criação de utensílios técnicos e as particularidades culturais (língua, vestimentas, alimentação, costumes). Porém, seu resultado mais importante é a formação de um vasto mosaico de gêneros de vida, isto é, diferentes capacidades de adaptação e modificação frente ao ambiente (VIDAL DE LA BLACHE, 1912:549). Portanto, a tarefa do geógrafo será sempre a de adquirir uma visão de conjunto, reunindo, essencialmente, três elementos: o homem, o meio e a técnica. 
Este é o centro da geografia vidaliana. Boa parte de seus artigos, com todas as variações que comportam, não deixam de girar ao redor disso. Les conditions géographiques des faits sociaux é um deles (VIDAL DE LA BLACHE, 1902). Como o próprio nome diz, cumpre ressaltar que os fatos sociais estão sujeitos a determinadas condições geográficas das quais não é possível manter-se à margem, pois parte da formação das sociedades são derivadas das respostas ao meio que elas mesmas engendraram historicamente. Numa abordagem que pode ser entendida como uma resposta a Durkheim e seus seguidores que, no final do século XIX, lançaram uma série de críticas à Geografia no L’Année Sociologique (RHEIN, 1982), Vidal procura subsídios onde seja possível assegurar que a constituição de traços sociais específicos encontrados em sociedades diferentes deve-se aos elementos geográficos.

Raciocinando assim, uma das causas da distinção entre as sociedades reside na posição. A floresta tropical africana dificultava imensamente a troca e o vínculo entre seus habitantes (embora o contato não fosse nulo, como aponta a amizade ou inimizade intertribal), de forma que as vilas eram um mundo à parte onde eles eram obrigados a retirar, engenhosamente, o que fosse necessário à sobrevivência. E, mesmo que o isolamento acontecesse por motivos religiosos, p.ex., tais grupos buscavam a solidão em sítios particulares, como os mais recuados vales, as clareiras abertas no meio da floresta siberiana ou a costa de Massachussets — revelando assim exemplos de uma "geografia social" (o termo é de Vidal).

Outra causa reside nos traços físicos de uma região: o conhecimento da fisionomia de um país causa impacto significativo em sua dinâmica migratória. Igualmente, a grandiosidade do território, a extrema divisão da propriedade e a necessidade de mão-de-obra tanto numerosa quanto hábil demandada pelo cultivo de arroz nas sociedades do Extremo Oriente, exigindo a participação das mulheres e dos vizinhos, acaba por fortalecer os laços familiares e da vila como um todo (VIDAL DE LA BLACHE, 1902).

De outro lado, cabe avaliar que o regime social também reflete na geografia, pois "tudo é ação e reação" (idem, p. 21). Dessa forma, Vidal quer dizer que há, em nome de interesses econômicos de certos grupos sociais, uma má utilização das potencialidades geográficas. É o que aconteceu com as grandes plantações de café. Nos EUA, elas submeteram a riqueza do solo, que poderia nutrir boa parte da população, a um único produto, e os negros "a uma das formas de escravidão mais odiosas e cruéis" (ibidem). No Brasil, critica o alto custo das mercadorias e do crédito impedindo o surgimento de pequenas propriedades, bem como a insalubridade do porto de Santos, escolhido pela proximidade com os centros produtores (ibidem, pp.21-22).

Não existiria, nas entrelinhas dessa retórica, uma justificativa para a exploração dos recursos coloniais? A alegação de que somente os europeus, dotados das mais avançadas técnicas, poderiam extrair as potencialidades adormecidas localizadas nos territórios d'outre-mer, beneficiando a "todos"? Suas palavras podem soar como advertência: "A existência de um produto de primeira necessidade, localizado em um espaço específico, pode engendrar consequências sociais e políticas” (ibidem, p.13, grifo nosso). Esse é o sentido social da geografia: a estratégia.

Em 1911, o autor supracitado publica dois artigos homônimos: Les genres de vie dans la géographie humaine aprofunda o exame das relações homem-meio, desenhando um jogo de forças em que a insistência do homem acarreta, pouco a pouco, a remodelação da natureza. Todavia, não se trata de uma conquista definitiva nem tampouco de uma via de mão única, mas sim de um novo arranjo em que homem e meio continuam a se agregar. É preciso realçar a capacidade de adaptação de ambos, pois o deslocamento humano sobre a superfície terrestre é, concomitantemente, o deslocamento de espécies animais e vegetais. Logo, a evolução dos gêneros de vida refere-se não apenas à competência técnica dos grupos sociais, mas também à plasticidade das espécies domesticadas e cultivadas.

Revista da ANPEGE. v. 6, 2010 (jan./dez.) 
Se ele conseguiu transformar a seu favor uma grande parte da Terra, não lhe faltam áreas onde foi derrotado. (...) Para constituir gêneros de vida que o tornassem independente das chances de alimentação cotidiana, o homem teve que destruir certas associações de seres vivos para formar outras. Teve que agrupar, por meio de elementos reunidos de diversos lados, sua clientela de animais e plantas, fazendo-se assim ao mesmo tempo destruidor e criador, quer dizer, realizando simultaneamente os dois atos nos quais se resume a noção de vida. (VIDAL DE LA BLACHE, 1911:200).

Porém, se Vidal arquiteta uma geografia da civilização (BUTTIMER, 1980), não se trata de uma ingênua relação homem-meio talhada culturalmente pelas civilizações. Ele a faz num período de profunda turbulência dos Estados-Nação europeus. Em outras palavras, trata-se da construção de uma geografia que, embora a história do pensamento geográfico consagrou como desinteressada do poder e da política em nome da ciência, se inscreve num espaço historicamente contextualizado (RIBEIRO, 2009a). Para a França pós-1870, as perdas não foram poucas: fraturados o território e a sociedade, ao adicionar as demandas advindas da empresa colonial, surgia um quadro em que as escalas nacional e internacional entrecruzavam-se e exigiam uma explicação. Não é por outra razão que o conhecimento geográfico será frisado, sob diferentes pontos de vista, como algo de extrema importância. Interessado na relação entre conhecimento, poder e espaço de produção do discurso, Edward Said enfatiza em Cultura e Imperialismo o papel jogado pela Geografia:

No Segundo Congresso Internacional de Ciências Geográficas, em 1875, a que compareceram o presidente da República, o governador de Paris e o presidente da Assembléia, o discurso inaugural do almirante La Roucière-Le Noury expôs a atitude predominante no encontro: 'Cavalheiros, a Providência nos ditou a obrigação de conhecer e conquistar a terra. Essa ordem suprema é um dos deveres imperiosos inscritos em nossas inteligências e nossas atividades. A geografia, essa ciência que inspira tão bela devoção e em cujo nome foram sacrificadas tantas vítimas, tornou-se a filosofia da terra. (SAID, 1995:221, grifo nosso [1993]).

Destarte, caberia ainda ensinar a leitura de cartas, descrever a diversidade regional e, com efeito, fortalecer a identidade nacional do cidadão francês. Aos poucos, a Geografia deixava de ser um catálogo toponímico e estatístico para assumir posição estratégica nos projetos de desenvolvimento da nação e do Império franceses. Suas virtudes consistiam também na promoção de trabalhos de campo e no mapeamento dos recursos naturais das colônias.

\section{DO SAARA AO MARROCOS, DO BRASIL AO CANADÁ: UMA VISADA GEOPOLÍTICA SOBRE A ÁFRICA E AS AMÉRICAS}

Poderia Vidal ter permanecido alheio a isso? A resposta só pode ser negativa. Participante ativo do movimento colonial (BERDOULAY, 1995 [1981]), foi um dos integrantes do projeto de reconstrução nacional após os anos 1870. Podemos começar pela resenha de La conquête du Sahara. Essai de psychologie politique, livro escrito em 1910 por Émile-Félix Gautier (1864-1940), professor de geografia geral e de geografia do Saara durante 35 anos na Faculdade de Letras da Universidade de Argel. Conhecido por suas obras sobre o Islam e a África do Norte, bem como por suas explorações a Madagascar e ao Saara, Berdoulay frisa cinco colaboradores regulares que dão uma "tonalidade colonial" aos Annales de Géographie (idem, p.68). Um deles é Gautier, para quem "a colonização francesa fez reviver as origens latinas do Império Romano" (PARIS, 1999:72).

Se não chega a tanto, Vidal compartiha com ele, pelo menos, duas idéias: (i) a missão francesa só poderia trazer benefícios aos colonizados. Nas palavras de Vidal, "o primeiro resultado de nossa intervenção será assegurar a todos a liberdade de movimentos que, até então, tinha sido privilégio de alguns" 
(VIDAL DE LA BLACHE, 1911b:75); (ii) estava em curso uma mudança nas idéias militares coloniais rumo àquilo que a imprensa consagrou como penetração pacífica, que seria algo como "uma mistura de diplomacia e força" (idem, p.74). Nesse sentido, repetindo a fórmula do general Lyautey, Vidal admitia que era melhor "Manifestar a força, para evitar empregá-la" (ibidem). Não obstante, pensa que esteja ocorrendo também uma mudança no "estado de espírito das populações" (ibid.) No entanto, enquanto essa mudança não se concretiza integralmente, Vidal é atraído pelo capítulo em que Gautier aborda a polícia do deserto, cujo êxito deveu-se à aplicação de uma tática utilizada pelas milícias de cossacos russos, que consiste em "atingir o inimigo empregando seus próprios meios de ataque" (ibid., p.76). Destarte, certamente que as qualidades guerreiras dos albanais do deserto não se perderiam, pois encontrariam emprego definitivo no quadro policial francês... (ibid.).

Seguindo agora a narrativa de viagem da missão Chari-Lac Tchad na África Central Francesa (19021904) escrita pelo botanista Auguste Chevalier (acompanhado de um geólogo e de um etnólogo), Vidal comenta que alguns de seus apêndices são dotados de "verdadeiro interesse geográfico" (VIDAL DE LA BLACHE, 1908: 166). Além de destacar os méritos metodológicos, como a comparação e a articulação passado-presente, afirma que o livro é um "testemunho preciso, ponderado, inspirado pelo desejo de servir à causa colonial" (idem, p.171). Passa em revista alguns dos problemas ocasionados pelas populações locais, como queimadas, modificações climáticas e decadência dos rios. Comentando o principal centro das explorações, a capital Ndélé do sultão Senoussi, atesta que este não passa de "um desses tipos de aventureiro político que, de tempos em tempos, abundam no Sudão africano" (ibidem, p.167).

Alerta às questões econômicas, diz que, embora a região conte com certos recursos agrícolas e pastorais, ela é, em geral, pobre. A criação de animais destinados ao uso do homem sofre com as doenças causadas pelos insetos e que não encontram remédio. A caça aos elefantes e a colheita da borracha, que tanto atraem o comércio europeu, logo se esgotarão. Seguindo o conselho do botânico, há que se introduzir culturas alimentícias - Vidal sugere o arroz - a fim de reconstituir a população, que caminha a largos passos em direção à extinção. Da posição de intelectual colonial um tanto quanto insatisfeito com as vias de desenvolvimento postas em prática naquela região, se pergunta: "Que fizemos para restaurar este país? Isso merece um exame de consciência" (ibid., p.171). E reconhece que os habitantes locais "espreitam a fome" (ibid). Sim, pois, na verdade, o que estava em jogo não eram os recursos naturais, a exploração da mão-de-obra ou o poderio político do Império francês, mas sim a "organização do capital humano, condição essencial de nossa ação colonial"... (ibid.).

Cioso face a essa ação, já que focos de conflito espalhavam-se por toda a parte, Vidal sabe que sua condição é privilegiada. Como geógrafo, estava capacitado a problematizar uma das questões mais delicadas da empreitada colonial: a delimitação das fronteiras, ponto de friç̧ão tanto entre impérios quanto entre estes e as populações autóctones. É o caso da zona entre a Argélia e o Marrocos, objeto de sua atenção em duas ocasiões (1897 e 1911). Nelas, não hesita em elogiar o trabalho realizado pelos militares franceses, nem tampouco em repreender o encaminhamento da política colonial quando esta se mostra ineficaz; resgata a dimensão histórica através de tratados e ratifica a importância da tomada e da manutenção dos territórios africanos. Em suas próprias palavras:

Os predecessores turcos de nossa dominação argelina tinham evitado intrometer-se nos negócios do Sul.

Tal abstenção estava proibida para nós e, com efeito, a aparição, desde 1845, de nossas tropas no sul oranês seguia de perto o tratado de Lalla-Marnia. Este foi o ponto de partida de uma série de complicações, das quais ainda estamos longe de ver o fim. A fundação do posto de Géryville, em 1852, marca nossa firma intenção de sustentar estes primeiros passos. Depois disso, quaisquer que tenham sido as hesitações de nossa política, tudo indica que, na engrenagem que nos arrasta, não saberíamos nos furtar por muito tempo à necessidade de fazer valer de autoridade em Touat. (VIDAL DE LA BLACHE, 1897:359-360).

Revista da ANPEGE. v. 6, 2010 (jan./dez.) 
Dominação, negócio, política e autoridade se misturam, tornando o Imperialismo uma empreitada altamente escorregadia. A proximidade da África do Norte com a Europa e seu histórico de zona de passagem só faziam acentuar a concorrência. Ali, as fronteiras eram extremamente móveis. Resguardá-las era uma operação assaz complexa. Vidal tinha plena consciência disso e, constatando a "má delimitação" (idem, p.362) das mesmas após o tratado de 1845 com o Marrocos, chamava atenção para o agravamento da ausência política francesa no vale de Molouïa, bem como distinguia suas consequências econômicas:

Porém, o que é mais grave é que se organiza sob os flancos de nossa colônia um movimento comercial que, partindo de Melilla, que os espanhóis erigiram em porto livre, fez penetrar as armas e os produtos europeus ao longo de nossas fronteiras até o sul. $\mathrm{O}$ desastroso aumento de nossas tarifas aduaneiras se acrescenta às causas que favorecem o tráfico rival. (...) Parece claro que a fronteira oranesa é um ponto doente em nossa colônia africana. (ibidem).

$\mathrm{O}$ que nos cabe assinalar é que o argumento de que existem fronteiras naturais delimitando regiões e territórios não faz aqui qualquer sentido. Pelo contrário, os geógrafos deveriam analisar os atritos fronteiriços:

É idéia de geógrafo que, numa zona territorial, depois de estudar o solo e seus habitantes, há que se estudar o fenômeno de contato entre regiões desigualmente civilizadas pois, por todos os lugares onde se produz, parece provocar, cedo ou tarde, um movimento de expansão ou de recuo. Encontramos estas condições no Marrocos, que se parecem com as da Rússia na Ásia e as da Inglaterra na Índia. (VIDAL DE LA BLACHE, 1911c:448).

Evocar uma disparidade civilizatória significa, na verdade, um recurso de linguagem a dissimular o fato de que existe um empecilho à organização colonial segundo a territorialidade eurocêntrica moderna. De acordo com Vidal, numa região em que historicamente as querelas são constantes, a organização social africana não corresponde às fronteiras estabelecidas diplomaticamente: a tribo Doui-Menia possui seus cultivos no baixo Guir, enquanto suas palmeiras localizam-se em outro lugar, Tafilelt. Assim, ele fica impressionado com a instabilidade dos grupos sociais e sua extrema pulverização territorial — "Este estado de querela parece o ar que se respira para estas sociedades" (idem, p.451), atesta — e, embora admita que o que pareça anarquia segundo os padrões europeus de Estado seja algo perfeitamente conciliável com sociedades elementares regidas por relações estritamente locais, preconiza que "o único meio de introduzir a segurança neste mundo inorgânico consiste em constituir agrupamentos; tarefa a qual o maghzen sempre se mostrou rebelde ou inepto" (ibidem). E, nesse particular, elogia (novamente) a participação do general Lyautey, que (im) pôs em prática a geo-grafia francesa. "Porta-voz" (nossas aspas) e modelo de soldado colonial, os escritos de Lyautey versavam sobre a obra de progresso e de paz promovida pelo Império (GIRARDET, 2007:125-126 [1972]).

Se não era um expedicionário, não restam dúvidas que os documentos e as ações militares atraíam a atenção de Vidal. O relatório do chefe da missão ao Peru em 1902, coronel Clément, em parceria com o tenente-coronel Bailly-Maitre, é um retrato disso. No empenho de conformação da Geografia como ciência, havia uma contribuição significativa das Forças Armadas que não podia (e não tinha razão de) ser ignorada. "Não uma simples viagem de estudos técnicos militares" (VIDAL DE LA BLACHE, 1906:79), mas um efetivo "reconhecimento geográfico" (idem) através da descrição do sítio e da topografia do terreno, produção e retificação de mapas e coleta empírica de dados. Não por acaso, estimulava a organização do Serviço Geográfico do Exército Peruano, "instrumento necessário para o estudo desta região interessante e mal conhecida" (ibidem). Portanto, para além de uma dicotomia frágil e sem sentido, "gabinete" e "campo" auxiliavam-se mutuamente: enquanto a ciência se beneficiava com as informações 
obtidas, os militares viam seus esforços tornados públicos e sendo louvados por uma revista de prestígio nos meios acadêmicos - alimentando e justificando, assim, novas intervenções.

Porém, mais do que concordar com a participação militar, Vidal demonstrava a pluralidade de suas funções, que se estendiam do território às esferas econômica, política e social. Mesmo não sendo uma colônia, a França atuava junto ao Peru exercendo o papel de Império, no intuito de ampliar áreas de influência, auxiliar na escolha do melhor caminho para o desenvolvimento do país e, naturalmente, obter vantagens desta aproximação. Seu pronunciamento é claro: "A questão das comunicações, vital para o Peru, liga-se diretamente às questões militares, que eram o objeto da viagem" (ibid.). Este era um dos graves problemas enfrentados pelo Peru, pois seu centro político e econômico, por causa dos acidentes do relevo, estava separado de sua principal via fluvial, a parte amazônica e o porto de Iquitos. O resultado direto era o encarecimento comercial, provocado pela necessidade de exportações. A situação parece se agravar quando, após a publicação das memórias de viagem, um sindicato mineiro norte-americano ampliou a via férrea de Oroya até Cerro de Pasco. O conselho francês era um só: havia que se precaver contra a formação de um monopólio. E, sinalizando para o alto custo do transporte de Lima a Iquitos, Vidal complementa:

Estas condições, deploráveis do ponto de vista econômico, podem, em certas eventualidades, tornar-se perigosas do ponto de vista militar. Uma das preocupações da missão foi, portanto, procurar o melhor traçado para 'a grande via central' da costa do Pacífico à Amazônia; via sem a qual o Peru não saberia assegurar sua individualidade política (...). (ibid., grifo nosso).

Uma vez anotados o meio - a floresta tropical como barreira entre os homens e foco de paludismo, mas sugere que a "região do futuro" (ibid., p.80) estaria localizada na zona de terras temperadas da bacia de Huanuco - e as dificuldades de estabelecimento de um grupo de colonos alemães na região de Montana - a 770m de altitude, manifestavam traços de degenerescência física, mas um grupo que vivia a 1800m mostrava que o êxito é possível —, Vidal retoma sua questão central com uma interrogação: "A despeito dos estabelecimentos europeus, uma rota verdadeiramente comercial e estratégica é possível?" (ibid., p.81). Ele fazia referência à região de Montana, onde se encontram "as origens da mais vasta rede de navegação fluvial existente no mundo" (ibid.). Entretanto, a despeito disso, havia muita a coisa se fazer, pois tanto a Sociedade Geográfica de Lima quanto a missão supracitada não reuniam dados suficientes para a definição do melhor traçado da rota. E finaliza:

Se este programa de trabalhos públicos, com os estudos prévios que ele supõe, for executado, veremos quanto a geografia teria a ganhar. Nossos compatriotas já estão empregados, segundo seus meios, em tornar este programa realizável. Desejamos que suas iniciativas, recompensadas por um novo contrato, continuem a se exercer em íntimo e cordial acordo com os interesses do país onde eles são hóspedes. (ibid., p. 82, grifo nosso).

Pronto: de uma só vez, estavam assegurados os ganhos científicos, o sucesso financeiro e a influência política francesa!

Mas a perspectiva geográfica vidaliana é deveras plural. Se sua atração pelos gêneros de vida nas regiões tropicais é uma realidade (VIDAL DE LA BLACHE, 1911), a relevância geopolítica das mesmas também o é. Qual a importância da presença francesa no Peru? Uma contra-ofensiva frente aos ingleses e norte-americanos na América do Sul? É possível. A proximidade com a Guiana Francesa? Com certeza. Sobre esta matéria, Vidal reclama da decisão diplomática do Conselho Federal Suíço frente às demandas da França: trata-se da perda de parte do território da Guiana para o Brasil em 1900. Afinal, o governo francês havia concedido ao próprio Vidal de la Blache a defesa de seu país, o que resultou na pesquisa 
La rivière Vincent Pinzon. Étude de la cartographie de la Guyane, apresentada àquele Conselho em 1899 mas publicada apenas em 1902 (cf. MERCIER, 2009).

Embora a decisão tenha sido benéfica no sentido da manutenção das boas relações com o Brasil e que, na realidade, o tema o atinja mais que à França, nem por isso a derrota devia ser menosprezada:

Não nos esqueçamos de alegar, antes como depois da sentença, uma vez que o eixo do nosso poderio colonial francês, hoje transportado na África e no sudeste da Ásia, que a questão não poderia ter para nós a mesma importância que para o Brasil. Entretanto, sem querer exagerar em nada, não seria exato dizer que a sentença que nos separou daqui em diante do território dito contestado seja para nós de consequências negligenciáveis. (VIDAL DE LA BLACHE, 1901:68).

A seguir, ressalta os sucessos das expedições francesas na região e conta com a compreensão do Brasil para que elas continuem acontecendo. Pelo menos, o litígio resultou na produção de mapas de ambos os lados, alguns inéditos e que, logo, haverá ocasião em que serão examinados. E diz que, se a questão política foi encerrada, talvez tenha sido melhor, pois abriu-se ao interesse científico - que, por sua vez, clarificará a contenda. Tal argumento se justifica da seguinte forma: lançando mão da cartografia a fim de tentar esclarecer a exata localização geográfica do rio Vincent-Pinçon (MERCIER, 2009: 31), Vidal desconfia que a região possa ter mais identidade com o Brasil que com a Europa:

Podemos dizer, sem faltar com o respeito à coisa julgada, que ela aplicou-se à interpretação de um artigo ambíguo [refere-se ao artigo 8 do tratado de Utrecht de 1713, assunto que os diplomatas franceses trataram, segundo ele, com desdém], introduzido em um instrumento diplomático. Mas, quanto à questão científica, permanece inteira. Existe identidade entre o rio que chamamos hoje Araguari e aquele que os espanhóis do século XVI, mestres e descobridores do país, chamavam rio de Vincent-Pinçon? Somente a análise de documentos originais revelaria esta causa. Se ele cessou como atualidade política, continua valendo a pena ser discutido como ponto de história. Nós não estamos bem informados sobre as antigas relações da Europa com esta parte do continente americano, de forma que este capítulo da história das descobertas foi observado como um objeto pouco digno de atenção. Talvez, depois de tudo isso, a ciência não deva se lamentar que a questão tenha sido deslocada dos interesses políticos que contribuiram para obscurecê-la. Daqui em diante, ela entra em seu verdadeiro terreno. As obras de polêmica e as teses apaixonadas serão confinadas no arsenal das velhas armas. A discussão, na presença apenas dos documentos, ganhará em esclarecimento. (VIDAL DE LA BLACHE, 1901:69-70).

Aqui, dois argumentos entram em cena: o primeiro é de matriz comteana-weberiana, ensaiando legitimar a separação entre ciência e política. Uma vez derrotado no campo humano, há que se buscar a compensação superior e neutra do intelecto. O segundo é o discurso histórico, onde os franceses não são mais franceses, mas europeus, tais como os espanhóis que conquistaram e descobriram a região. A diferença vira identidade e o passado, se não corrige, ao menos ameniza as distorções do presente.

Porém, tal discurso não passa de uma miragem. Mapeando agora as áreas de influência européia na América do Norte, o autor em tela resenha La mise en valeur de la Colombie britannique (1907), tese de doutorado de Albert Métin. De início, realça a visada geográfica que perpassa a tese como um todo (o enquadramento do meio), bem como demonstra uma postura eurocêntrica na afirmação de que algumas tribos indígenas adaptaram-se de tal forma às estradas de ferro que foram elevadas a um certo grau de civilização (VIDAL DE LA BLACHE, 1908a:365). Em seguida, focaliza os componentes econômicos do domínio inglês no Canadá, tais como a extração de matérias-primas (chumbo e cobre) e metais preciosos (ouro) e o fraco impulso da agricultura. Sendo a "colônia da colônia" (idem, p.366), a região permaneceu praticamente relegada - salvo pelos caçadores profissionais (que exterminaram quase por completo as 
lontras do mar e as focas que atraíam pescadores de todos os lados), por alguma contenda fronteiriça ou por qualquer alerta de prospecção de ouro.

A situação começou a mudar quando da conclusão da Canadian Pacific, que inseriu a Colúmbia britânica no mercado mundial. Porém, incrivelmente, a chegada do "progresso" (as aspas são nossas) não é vista com bons olhos por Vidal, que critica capitalistas, especuladores e engenheiros dispostos a extrair o máximo de lucro da terra da melhor forma possível. Trata-se do "fenômeno americano por excelência" (ibidem): sua fórmula make money (que atinge também o México, conforme ele mesmo indica) "permanece o objetivo supremo e a preocupação dominante destas sociedades utilitárias. A Colúmbia britânica aproveita a dominação inglesa e vive do americanismo" (ibid.).

Ora; tal declaração não deve ser motivo de estranheza, mas sim da mais absoluta normalidade: se de um lado Vidal cerra os olhos para as atrocidades da colonização francesa, preferindo elogiar as medidas tomadas por seus militares, de outro lado é lícito censurar não só o velho inimigo inglês, mas também a jovem nação norte-americana.

\section{VIDAL PENSADOR DA EUROPA: a geopolítica em La France de l'Est}

Do ponto de vista geopolítico, outro momento em que Vidal de la Blache declara de maneira enfática seu engajamento para com a empreitada colonial francesa é em La France de l'Est: Alsace-Lorraine (VIDAL DE LA BLACHE, 1994 [1917]). Numa escala mais ampla e tendo o Imperialismo como pano de fundo, o capítulo "Du principe de groupement dans l'Europe Occidentale" indica aguda percepção em torno da geopolítica européia. Muitas passagens são extremamente atuais: abordando o tema das identidades nacionais, defende a autonomia de pequenos Estados como Holanda, Bélgica, Suíça e Portugal; elogia os acordos políticos entre Inglaterra e Escócia e entre o Norte e o Sul da França após um passado de guerras; sustenta que a história da Europa é uma história de mistura de raças, numa argumentação útil contra a xenofobia e a favor do multiculturalismo; em nome das noções de liberdade e justiça, prega a rejeição da superioridade racial e do ressentimento de lutas passadas (VIDAL DE LA BLACHE, 1994: 205-213 [1917]).

No entanto, o que mais se destaca é sua preocupação com a retomada da paz e com o desenvolvimento do capitalismo europeu. Para isso, era preciso restabelecer o status quo. Ainda que não diga explicitamente, sugere que o melhor caminho a ser seguido pela Europa seria não o expansionismo interno, mas o externo, numa partilha que respeitasse as conquistas históricas dos Impérios e se estruturasse a partir de acordos internacionais - o que favoreceria França e Inglaterra em detrimento da Alemanha. Esta deveria percorrer a mesma senda de Grã-Bretanha, França e Rússia, "que encontraram na África e na Ásia seus campos de expansão" (idem, p.197).

Evidentemente, Vidal não tinha motivo algum para ser simpático com o outro lado do Reno. Afinal, a "mutilação de 1871" — era assim que ele se referia à perda da Alsácia-Lorena (ibidem, p.149) — provocara claros prejuízos econômicos ao Hexágono. Todavia, ao se opor aos métodos alemães de desenvolvimento associados à extensão territorial, poderio militar e exploração de recursos naturais, e acusar o país vizinho de estar fora dos princípios políticos de cunho civilizatório que a Europa historicamente edificou (ibid., p.208-209), ele enxerga na ameaça alemã a possibilidade de uma aliança continental com as forças "do Leste e do Oeste", numa Europa organizada sob "bases mais largas" (ibid., p.210).

Aqui, Vidal resgata uma questão clássica da geopolítica européia e assume postura importante, fazendo entrar em cena um ator temido porém incapaz de ser negligenciado: a Rússia. Ao destacar a força de seu território e de seus recursos, ele se opõe contra a posição de isolá-la, conclamando vigorosamente por sua participação na "comunidade européia" (ibid., p.213). E, por conta de uma política externa "hesitante", 
chega mesmo a responsabilizá-la pelo êxito das ambições alemãs — ao lado de uma França "desamparada" e de uma Inglaterra "ainda iludida" com o germanismo (ibid., p.196).

Entretanto, bastante preocupado com as conquistas territoriais e a centralidade do Império Alemão - mais bem localizado para a dominação do continente do que jamais tiveram o Império Romano ou Napoleão (ibid., p.196) —, o que podemos deduzir é que não caberia à outra nação senão à Rússia papel cabal num provável conflito de proporções mundiais. Conforme seu registro:

Diante do espetáculo destes formigueiros humanos, destas cidades crescentes por todos os lados, um observador poderia se perguntar se não estaria assistindo à formação de algo novo, de um Estado ultrapassando os quadros que a história parecia ter destinado à maioria dos Estados europeus, capaz de, um dia, disputar mesmo com a Rússia a vantagem da extensão. Se tal pensamento viesse acometer o espírito do visitante, imagine se ele arraigasse no espírito do alemão! O crescimento no sentido material, a extensão, o Raum seguindo a expressão dos seus teóricos da geografia política —, é a medida da vitalidade e da saúde de um Estado. (ibid., p.197).

Ainda que redigido no calor da Guerra de 1914, ao chamar atenção da Europa para os perigos do imperium (o termo é dele) germânico, reprovar a incapacidade da "diplomacia ocidental" por não perceber as ambições alemãs, desmentir alguns de seus argumentos sobre a necessidade do expansionismo e convocar a Rússia como aliada, uma leitura em retrospectiva não teria dificuldades de acusar seu espectro profético: a iminência da II Guerra Mundial.

Numa verdadeira lição de diplomacia e política externa, ele constata que o tempo do isolamento internacional havia terminado, reconhece a divergência de interesses e praticamente antevê a geopolítica atual, onde economia e política são indiscerníveis e a globalização consolidou o arranjo dos Blocos:

Quando refletimos sobre as condições que a crescente complicação dos interesses internacionais criou entre os povos, não tardamos a nos persuadir que uma ação isolada não corresponde nem à ordem das coisas e nem a interesses particulares. Os tempos do 'esplêndido isolamento' passaram mesmo para aqueles que o Oceano parecia resguardar. Há muita repercussão nos negócios do mundo para que se possa eximir-se da preocupação de não estar seguindo seu progresso. Além disso, como estamos longe de ter alcançado um grau ideal de civilização onde antagonismos mais ou menos irredutíveis deixarão de preocupar, é mister se organizar para combinar os interesses que sejam conciliáveis e, ao mesmo tempo, para fazer frente às intenções adversas. É assim que agrupamentos são formados — não sob o reino de necessidades fugazes, mas como uma assistência mútua contraída com vistas ao futuro. A noção de grupos tende a substituir a noção de Estado na condução dos negócios mundiais. (ibid., p.205, grifo nosso).

Tomando tais reflexões num sentido mais geral, do desmembramento do Império Napoleônico à recomposição republicana do "mutilado" território francês, passando pelas perdas econômicas e políticas dele resultantes, distinguimos um geógrafo cujos argumentos caminhavam pari passu com o imperativo histórico que se apresentava diante de seus olhos: as fronteiras francesas foram e continuariam sendo delimitadas na arena política dos conflitos sociais. Não havia uma providência metafísica que ligasse o destino da França a um espaço exclusivamente seu. Se o conceito moderno de Europa nascera exatamente em função de uma nova forma de organização espacial - os Estados Nacionais — onde o território era um dos principais pilares, Vidal sabia que malogros militares e diplomáticos custariam caro.

Por isso ele lamentara o tratado de 1814, que custou treze departamentos na Bélgica e no lado esquerdo do Reno. Pelo mesmo motivo, fora veemente no tocante à participação ativa da França na confecção do mapa internacional do mundo ao milionésimo em 1909, sob o risco de ver suas colônias mapeadas por países como Inglaterra, EUA e Alemanha (VIDAL DE LA BLACHE, 1919, 1910, respectivamente). 
De qualquer maneira, a vitalidade geopolítica de La France de l'Est não supera o fato de que, para nós, seu leitmotiv é majoritariamente econômico. Se é verdade que os fins justificam os meios, Vidal o fez operando o território como meio para atingir um fim econômico. É assim que a relevância da "AlsáciaLorena" para a França é menos cultural e identitária do que econômica. Não que ele não estivesse atento àqueles aspectos, muito pelo contrário. Construindo uma visão "parisiense" um tanto quanto ingênua e ideal sobre a Lorena (BONNEFONT, 1993), sua obstinação nacionalista em engendrar um discurso científico que justificasse em definitivo os vínculos desta e da Alsácia à França o levou a acusar de "pangermanista" (VIDAL DE LA BLACHE, 1994:88 [1917]) o geógrafo Bertrand Auerbach —à época professor de geografia na Faculdade de Letras de Nancy e que já havia publicado nos Annales, periódico criado pelo próprio Vidal de la Blache! - , posto que ele admitia a separação da Alsácia germanófila frente à Lorena. Outros geógrafos de Nancy também reconheciam certas especificidades desta última e seu distanciamento para com a França (BONNEFONT, 1993).

Todavia, cremos que sua inquietação reside menos no caráter estratégico da "França do Leste" do que no fato de que sua perda acarretou diretamente o enfraquecimento da economia nacional. Após o Tratado de Frankfurt, a fração territorial que coube à França lhe parecia incapaz de sustentar por si mesma a força industrial de outrora: eram as filatures alsacianas que alimentavam os tecidos vosgianos; os centros metalúrgicos mais ricos da Moselle agora eram alemães. "O que nos restou senão migalhas?", indignava-se (VIDAL DE LA BLACHE, 1994:146 [1917]). No entanto, para ele, os laços econômicos entre Alsácia e Lorena seriam fortes o suficiente para que uma espécie de "continuidade regional pudesse sobreviver à separação política" (idem, p.150). De maneira semelhante, ao abordar as colônias ele é categórico: face aos "desafios econômicos", há que se tirar "todo proveito possível" de seus territórios (ibidem, p.261).

\section{CONSIDERAÇÕES FINAIS}

Os casos analisados até então anunciam que, em Vidal, a preocupação patriótica e a promoção do Império se entrelaçam (vide também NICOLAS-OBADIA, 1987; GUANZINI \& NICOLAS-OBADIA, 1988). Assim sendo, do ponto de vista geopolítico, Vidal não está tão distante assim de Ratzel como queria o historiador Lucien Febvre (FEBVRE, 1922; MERCIER, 1995). Embora a linguagem, a démarche e a visão sobre a guerra e a expansão territorial não fossem as mesmas, ambos estavam convencidos de que território e poder eram sinônimos. Por isso Vidal admitia que a geografia política podia ser estendida ao conjunto da geografia humana (VIDAL DE LA BLACHE, 2002:123 [1898]). Esta seria o estudo das múltiplas estratégias estabelecidas pelos grupos sociais em busca do pleno desenvolvimento. "Múltiplas estratégias" quer dizer as várias formas de adaptação ao meio distribuídas sobre a superfície terrestre, mas também os jogos econômico e político perseguindo os melhores recursos e as melhores posições. "Grupos sociais" quer dizer caçadores, pastores e nômades, mas também os Estados Nacionais repartindo os territórios como um enorme tabuleiro de xadrez em disputa.

À luz da investigação documental e sua problematização (etapa incontornável no âmbito da renovação do campo da história do pensamento geográfico e da escrita da geografia), esperamos ter apontado os fortes vínculos de Vidal de la Blache com a geopolítica. Um olhar atento ao contexto histórico de surgimento e desenvolvimento da geografia universitária na França nos mostra claramente que, da Guerra FrancoPrussiana à II Guerra Mundial, era praticamente impossível que a produção científica permanecesse alheia ao que estava acontecendo ao seu redor . Assim, do alto da posição de um dos maiores intelectuais de seu tempo, Vidal não abriu mão de refletir sobre questões que afetavam diretamente a nação francesa na Europa e o Império francês no mundo .

Revista da ANPEGE. v. 6, 2010 (jan./dez.) 
Nesse sentido, um dos aspectos merece relevo diz respeito à forma como Vidal apropriou-se da Geografia, uma forma que explorou habilmente a ambiguidade do discurso geográfico. Tratava-se, sutilmente, de modificá-lo não apenas por interesses opostos — o que seria óbvio demais —, mas segundo o lugar a ser objeto de discussão. O apelo de que a geografia atuava no sentido da convergência, fazendo emergir as virtudes do encontro e das trocas entre habitantes de lugares variados, só seria válido quando do imperativo de edificar um discurso cuja retórica não era outra senão a de forjar um sentimento de unidade nacional. Na França e para os franceses, a geografia constituir-se-ia em canal de aglutinação, fonte inata de câmbios entre o Midi e o Norte, a Bretagne e o Leste, espaço liso e pacífico a permitir a

livre circulação de seus cidadãos . Na África, nas Américas e no mundo, em meio a ingleses, alemães, italianos e belgas, a geografia sofre uma metamorfose, tornando-se instrumento de desavença, terreno sinuoso que dispersava e atritava povos, ambientes e culturas segundo os valores econômicos, políticos e sociais dos territórios colonizados e dos negócios coloniais. Nestes continentes, as "regiões naturais" não possuíam a harmonia dos agricultores e pastores, mas sim eram exploradas por engenheiros e geólogos, protegidas por exércitos e cartografadas segundo seus recursos.

Uma geografia simplória e enfadonha? Não a de Vidal de la Blache.

\section{AGRADECIMENTOS}

Agradeço a leitura atenta, os comentários enriquecedores e o incentivo de Paul Claval (Paris IV Sorbonne) a propósito de nossas investigações sobre Vidal de la Blache.

\section{REFERÊNCIAS BIBLIOGRÁFICAS}

BERDOULAY, Vincent. La formation de l'école française de géographie. Paris: Éditions du CTHS, 1995 [1981].

BONNEFONT, Jean-Claude. La Lorraine dans l'oeuvre de Paul Vidal de la Blache. In: CLAVAL, Paul (dir.). Autour de Vidal de la Blache. La formation de l'école française de Géographie. Paris: Éditions du CNRS, 1993.

BUTTIMER, Anne. Sociedad y medio en la tradición geográfica francesa. Barcelona: Oikos-Tau, 1980.

CLAVAL, Paul. Géographies et géographes. Paris: L'Harmattan, 2007.

CLAVAL, Paul. National Schools of Geography. In: KITCHIN, Rob, THRIFT, Nigel (eds.). International Encyclopedia of Human Geography. London: Elsevier, 2009.

DEPREST, Florence. Géographes en Algérie (1880-1950). Savoirs universitaires en situation coloniale. Paris: Belin, 2009.

FEBVRE, Lucien. La terre et l'évolution humaine. Paris: La Renaissance du Livre, 1922.

GIRARDET, Raoul. L'idée coloniale en France de 1871 à 1962. Paris: Hachette, 2007 [1972].

LACOSTE, Yves. La Géographie, ça sert, d'abord, à faire la guerre. Paris : Maspéro, 1976.

LACOSTE, Yves. Préface. In : VIDAL DE LA BLACHE, Paul. La France de l'est (Lorraine-Alsace). Paris: La Découverte, 1994 [1917].

MERCIER, Guy. La région et l'État selon Friedrich Ratzel et Paul Vidal de la Blache. Annales de Géographie, n. $583,1995$.

MERCIER, Guy. Paul Vidal de la Blache ou la légitimation patriotique de la région et de la géographie. Revue Française de Géoéconomie, n. 5, printemps, 1998. 
MERCIER, Guy. Entre science et patrie. Lecture du régionalisme de Paul Vidal de la Blache. Cahiers de Géographie du Québec, vol. 45, n.126, déc., 2001.

MERCIER, Guy. La géographie de Paul Vidal de la Blache face au litige guyanais : la science à l'épreuve de la justice. Annales de Géographie, n. 667, 2009.

NICOLAS-OBADIA, Georges. Paul Vidal de la Blache et la politique. Bulletin de l'Association Géographique Française, 4, 1988.

NICOLAS-OBADIA, Georges; GUANZINI, C. Géographie et Politique: Paul Vidal de la Blache. EratostheneMeridien, 1, 1987.

OZOUF-MARIGNIER, Marie-Vic, ROBIC, Marie-Claire. La France au seuil des temps nouveaux. Paul Vidal de la Blache et la régionalisation. L'Information Géographique. Paris, vol. 59 , 1995.

PARIS, Erato. La genèse intellectuelle de l'oeuvre de Fernand Braudel. Athènes: Institut de Recherches Néohelléniques/FNRS, 1999.

RHEIN, Catherine. La Géographie, discipline scolaire et/ou science sociale? (1860-1920). Revue Française de Sociologie, Paris, XXIII, nº 23-2 (1982).

RIBEIRO, Guilherme. Interrogando a ciência: a concepção vidaliana de Geografia. Confins [On line], 8, 2010a. URL: http://confins.revues.org/6295

RIBEIRO, Guilherme. Em luta pela autonomia e pelo território: a Geografia e os Estados alemão e francês na virada do século XIX para o século XX. Mercator (UFC), ano VIII, n. 15, 2009a. pp.19-28,

RIBEIRO, Guilherme. Para ler Geografia ou A Geografia segundo Lucien Febvre. Terra Livre, n.32, ano 25, 2009.

RIBEIRO, Guilherme. Para além da ingenuidade: releituras vidalianas. Geographia (UFF), ano X, n. 20, 2008.

RIBEIRO, Guilherme. Uma epistemologia em construção: diálogos entre a Geografia e a Sociologia em Paul Vidal de la Blache. Geographia (UFF), ano IX, n. 18, 2007.

SAID, Edward. Camus e a experiência colonial francesa. In: SAID, Edward. Cultura e Imperialismo. São Paulo: Cia. das Letras, 1995 [1993].

SANGUIN, André-Louis. Vidal de la Blache et la géographie politique. Bull. Assoc. Géogr. Franç., Paris, 4, 1988. SINGARAVÉLOU, Pierre (éd.). L'Empire des géographes. Géographie, exploration et colonisation (XIXe-Xxe siècles). Paris : Belin, 2008.

SOUBEYRAN, Olivier. Imaginaire, science et discipline. Paris : L’Harmattan (1997).

THIESSE, Anne Marie. La petite patrie enclose dans la grande: regionalismo e identidade nacional na França durante a Terceira República (1870-1940). Estudos Históricos, Rio de Janeiro, vol. 8, n. 15 (1995).

VIDAL DE LA BLACHE, Paul. La Péninsule européenne. L'Océan et la Méditerranée. Leçon d'ouverture du cours d'histoire et géographie à la Faculté de Lettres de Nancy. Paris et Nancy: Berger-Levrault, 1873.

VIDAL DE LA BLACHE, Paul. États et nations de l'Europe autour de la France. Paris: Delagrave, 1889.

VIDAL DE LA BLACHE, Paul. La zone frontière de l'Algérie et du Maroc, d'après de nouveaux documents, Annales de Géographie, année VI, nº $28,1897$.

VIDAL DE LA BLACHE, Paul. A Geografia Política. A propósito dos escritos de Friedrich Ratzel. Geographia, Revista do Programa de Pós-Graduação em Geografia da UFF. Niterói/Rio de Janeiro, UFF/EGG, nº 7, ano 4, 2002 [1898].

Revista da ANPEGE. v. 6, 2010 (jan./dez.) 
VIDAL DE LA BLACHE, Paul. Le contesté franco-brésilien. Annales de Géographie, année X, no 49, 1901.

VIDAL DE LA BLACHE, Paul. Les conditions géographiques des faits sociaux. Annales de Géographie, année XI, no 55, pp.13-23, 1902.

VIDAL DE LA BLACHE, Paul. Routes et chemins de l'ancienne France. Strates [En ligne]. Crises et mutations des territoires, $n^{\circ}$ 9, 1996-97 [1902].

VIDAL DE LA BLACHE, Paul.La France. Tableau géographique. In: RIOUX, Jean-Pierre. Tableaux de la France. Michelet, Duruy, Vidal de la Blache et Bruno. Paris: Omnibus, 2007 [1903].

VIDAL DE LA BLACHE, Paul. La mission militaire française au Pérou. Annales de Géographie, année XV, $n^{\circ}$ $79,1906$.

VIDAL DE LA BLACHE, Paul. L'Afrique Centrale Française, par A. Chevalier. Annales de Géographie, année XVII, nº 92, 1908.

VIDAL DE LA BLACHE, Paul. La Colombie Britannique, par A. Métin. Annales de Géographie, année XVII, $\mathrm{n}^{\circ}$ 94, 1908a.

VIDAL DE LA BLACHE, Paul. La carte internationale du monde au milionième. Annales de Géographie, année XIX, n. 103, 1910.

VIDAL DE LA BLACHE, Paul. Les genres de vie dans la géographie humaine. Premier article. Annales de Géographie, année $\mathrm{XX}, \mathrm{n}^{\circ} 111,1911$.

VIDAL DE LA BLACHE, Paul. Les genres de vie dans la géographie humaine. Deuxième article. Annales de Géographie, année XX, nº 112, 1911a.

VIDAL DE LA BLACHE, Paul. La conquête du Sahara d'après E. F. Gautier. Annales de Géographie, année XX, $\mathrm{n}^{\circ} 109,1911 \mathrm{~b}$.

VIDAL DE LA BLACHE, Paul. Les confins algero-marrocains, d'après le livre de Augustin Bernard. Annales de Géographie, année XX, $\mathrm{n}^{\circ} 114,1911 \mathrm{c}$.

VIDAL DE LA BLACHE, Paul. Sur le sens et l'objet de la géographie humaine. Revue politique et littéraire, n.17, 1er sem, 1912.

VIDAL DE LA BLACHE, Paul. La France de l'est (Lorraine-Alsace). Paris: La Découverte, 1994 [1917].

VIDAL DE LA BLACHE, Paul. La frontière de la Sarre, d'après les traités de 1814 et de 1815 . Annales de Géographie, XXVIII année, $n^{\circ} 151,1919$.

Recebido em setembro de 2010

Aceito em dezembro de 2010 